\title{
Comparison of integrated fuel processing options for biogas- fed solid-oxide fuel cell plants
}

\author{
Shuai Ma ${ }^{1,2, \dagger}$, Gabriele Loreti ${ }^{2,3, \dagger}$, Ligang Wang ${ }^{2,4,1, *}$, Andrea Luigi Facci ${ }^{3}$, Stefano Ubertini ${ }^{3}$, Changqing Dong ${ }^{1}$, \\ François Maréchal ${ }^{4}$, Jan Van herle ${ }^{2}$ \\ ${ }^{1}$ National Engineering Laboratory of Biomass Power Generation Equipment, North China Electric Power University, Beijing \\ 102206, China \\ ${ }^{2}$ Group of Energy Materials, Swiss Federal Institute of Technology in Lausanne, Sion 1951, Switzerland \\ ${ }^{3}$ School of Engineering, Department of Economics, Engineering, Society and Business Administration, University of Tuscia, \\ 01100 Viterbo Italy \\ ${ }^{4}$ Industrial Process and Energy Systems Engineering, Swiss Federal Institute of Technology in Lausanne, Sion 1951, Switzerland
}

\begin{abstract}
The Solid-oxide fuel cell is a highly efficient prime mover for biogas conversion, but a part of biogas needs to be reformulated externally to facilitate the electrochemical conversion, easy control of reforming conditions, and thermal management of the stack. Carbon deposition and external mineralcarrying water should be avoided to ensure the durability of the fuel processor and stack catalysts. This paper investigates four plant layouts with different anode off-gas recirculation schemes and biogas reforming methods: (1) pre-reforming with hot recirculation (HR), (2) pre-reforming with cold recirculation (CR), (3) no pre-reforming and hot recirculation (NR), (4) partial oxidation with hot recirculation (PO). All the schemes feature an electrolyte supported SOFC working at $860{ }^{\circ} \mathrm{C}$ and 0.23 $\mathrm{A} / \mathrm{cm}^{2}$ current density. A sensitivity analysis of the plant efficiency as a function of the Recirculation Ratio (RR) and the Reformer Temperature (RT) is performed. The results show that HR and CR schemes achieve the highest efficiency (58-63\%). The HR scheme benefits from the recirculated water and does not require external water for RR $>50 \%$ and $\mathrm{RT}>600{ }^{\circ} \mathrm{C}$; the $\mathrm{CR}$ scheme achieves the same result for $\mathrm{RR}>80 \%$ and $\mathrm{RT}>700{ }^{\circ} \mathrm{C}$. The optimal RR is within $50-80 \%$ for the highest system efficiency, as a trade-off between the overall fuel utilization and electrochemistry performance. The RT should be between 600 and $700{ }^{\circ} \mathrm{C}$. The HR scheme is the overall best performing if the re-circulator and stack designs do not limit the flow rates at a high RR.
\end{abstract}

\section{Introduction}

SOFCs (Solid Oxide Fuel Cells) have high electrical efficiency [1] compared to traditional systems with low emissions and high fuel flexibility $[2,3,4]$. Biogas-fed SOFC system can produce clean electricity and heat at potentially low costs, boosting the biogas production sites potential. The hydrogen of electrochemical conversion in the stack stems from the reformulated biogas. Wet reforming with steam $\left(\mathrm{CH}_{4}+2 \mathrm{H}_{2} \mathrm{O} \rightarrow\right.$ $3 \mathrm{H}_{2}+2 \mathrm{CO}$ ) [5], dry reforming with carbon dioxide $\left(\mathrm{CH}_{4}+\mathrm{CO}_{2} \rightarrow 2 \mathrm{H}_{2}+2 \mathrm{CO}\right)[6]$, mixed reforming with both steam and carbon dioxide, or partial oxidation of biogas $\left(\mathrm{CH}_{4}+\mathrm{O}_{2} \rightarrow \mathrm{CO}_{2}+2 \mathrm{H}_{2}\right)$ [7] are possible biogas processing options.
Two factors affect the performance and the durability of biogas SOFC plants: external water supply for biogas reforming, (2) carbon deposition. The minerals in externally supplied water and the carbon formed can deposit reducing catalysts activity and increasing the mass diffusion resistance. Therefore, a proper system design aims to reduce the dependency on external water while avoiding carbon deposition.

The dry reforming and partial oxidation of biogas can reduce the external water need. However, the resulting carbon fraction in the reactants (between 33\% and $100 \%$ ) can lead to carbon deposition. Partial oxidation of biogas is also a candidate to reduce the need for external water. The biogas oxidation process is an

\footnotetext{
$1_{\uparrow}$ These authors contributed equally to this work

${ }^{\star}$ Corresponding author: ligang.wang@epfl.ch
} 
exothermic reaction and produces water, so combining the methane oxidation reaction with steam reforming in a reactor can achieve autothermal reforming, but will reduce system efficiency with a low biogas conversion.

The external reforming of the SOFC can carry out the fuel reforming reaction without affecting the original structure of the system, but the additional reformer greatly increases the system cost. The internal reforming enables the fuel to proceed inside the SOFC and absorb the heat released by the SOFC electrochemical reaction, greatly saving heat and energy, but the reforming catalyst is easily polluted.

Therefore, in this paper, we study four plant layouts considering different recirculation options of anode offgas and biogas reformulation methods. A sensitivity analysis on the plant efficiency as a function of the recirculation temperature (RT) and reforming temperature (RT) is performed to identify the feasible design zones with no carbon deposition risk. The different schemes are compared in terms of the plantwise heat integration and the highest feasible efficiency.

\section{Plant layouts and biogas composition}

The four plant layouts with different biogas processing (Fig. 1) are (1) pre-reforming with hot recirculation (HR), (2) pre-reforming with cold recirculation (CR), (3) hot recirculation mixed without reformer (NR), (4) partial-oxidation with hot recirculation (PO). The difference between $\mathrm{CR}$ and HR schemes is that the CR employs a drum to knock-out most of the water. Thus, the $\mathrm{CR}$ is $\mathrm{CO}_{2}$-dominated, and $\mathrm{HR}$ is steam-dominated. The NR does not adopt an external reformer and the raw biogas is fully reformed inside the stack. The PO scheme provides the steam and $\mathrm{CO}_{2}$ for methane reforming with direct oxidation of a part of the methane fed, leading to a simple process layout with auto-thermal biogas reforming. The amount of methane directly oxidized is decided by the selected SCR.

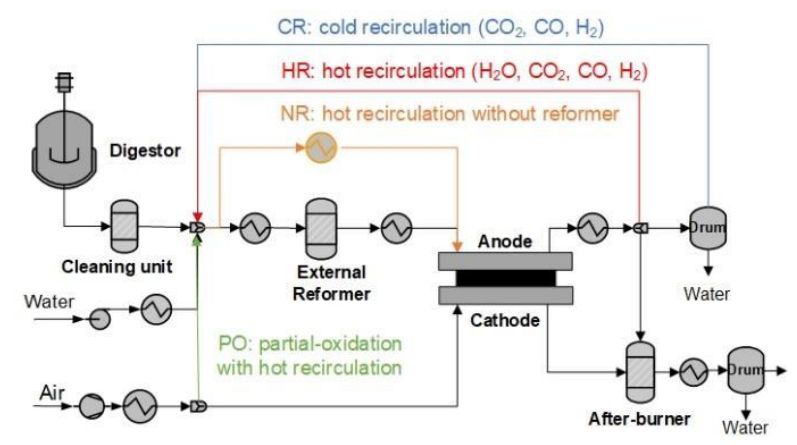

Fig. 1. Schematic representation of the 4 plant layouts with different options of anode off-gas recirculation and reforming.

The mix of raw biogas, recirculated gas, external water (if needed), and air (if needed) is heated and enters the external reformer with a certain amount of biogas reformed to hydrogen. Then, the pre-reformed syngas is heated by the heat exchanger to the stack operating temperature and enters the anode. A fraction of anode exhaust can be recirculated to supply steam and $\mathrm{CO}_{2}$ for the biogas reforming, while the remaining goes to the afterburner.

The air is heated and enters the cathode to supply oxygen for the electrochemical reaction and to cool the stack. The hot air out of the cathode goes to the afterburner to burn the anode off-gas. The afterburner flue gas is then cooled with the process heated recovered to satisfy the process's heat demands.

The types of biomass and digester determine the bulk composition of the biogas. However, for the most common feedstocks (agricultural manure biomass, organic fraction of municipal solid waste, landfill biomass), the derived biogas typically contains 53-58 vol. $\% \mathrm{CH}_{4}$ and $35-38$ vol. $\% \mathrm{CO}_{2}$. The main impurity gases are $\mathrm{N}_{2}$ and $\mathrm{O}_{2}$ due to the Sulphur removal process for biogas cleaning. Considering the limited difference, we select the biogas composition (vol.\%) of $\mathrm{CH}_{4} 57$, $\mathrm{CO}_{2} 37, \mathrm{~N}_{2} 4.74, \mathrm{O}_{2} 1.2$ for this paper.

\section{Methodology and specifications}

\subsection{Components modeling}

The systems described in section 2 are modeled through a steady-state, lumped parameter approach implemented in Aspen Plus [8]. All chemical reactors involved are based on the GIBBS reactor to predict the composition under chemical equilibrium $[9,10]$. All relevant chemical reactions, including dry/steam methane reforming, partial oxidation, and water-gas shift reaction, are considered.

Leveraging from the process simulation, we determine the optimal heat integration scheme of the plant with a MILP-based approach $[11,12]$. Therefore, the heat exchangers in the process simulation are represented by separate heaters and coolers to identify the heat and cold demand.

The model for the electrolyte-supported cell is based on zero-dimensional electrochemical performance, represented by Nernst potential and area-specific resistance. The $0-\mathrm{D}$ model is calibrated with performance data from the industry. The temperature of the stack is controlled by the air flow. The stack operating conditions are: atmospheric pressure, mean operating temperature $860{ }^{\circ} \mathrm{C}$, current density 0.235 $\mathrm{A} / \mathrm{cm}^{2}$, oxygen utilization rate $10 \%$, and after-burner temperature $900{ }^{\circ} \mathrm{C}$. Such parameters are fixed for all the plant configurations.

\subsection{Sensitivity analysis}

The sensitivity of the plant efficiency on the RR from 0 to $90 \%$ and RT from $300-800{ }^{\circ} \mathrm{C}$ is performed in the following ranges:

The overall calculation procedure is reported in Fig. 2. For each combination of RR and RT, the minimum $\mathrm{SCR} \quad\left(\mathrm{SCR}=\frac{\dot{n}_{\mathrm{H} 2 \mathrm{O}}^{\text {fuel-mix }}}{\dot{n}_{\mathrm{CH} 4}^{\mathrm{fuel}-\mathrm{mix}}}=\frac{\dot{n}_{\mathrm{H} 2 \mathrm{O}}^{\text {added }}+\dot{n}_{\mathrm{H} 2 \mathrm{O}}^{\text {rec }}}{\dot{n}_{\mathrm{CH} 4}^{\text {biogas }-\mathrm{in}_{2}+\dot{n}_{\mathrm{CH} 4}^{\mathrm{rec}}}}\right.$, where the $\dot{n}_{\mathrm{H} 2 \mathrm{O}}^{\text {added }}$ is the additional water supplied externally for 
reforming, the $\dot{n}_{\mathrm{CH} 4}^{\text {biogas-in }}$ is the methane in the biogas fed into the system. The $\dot{n}_{\mathrm{H} 2 \mathrm{O}}^{\mathrm{rec}}$ and $\dot{n}_{\mathrm{CH} 4}^{\mathrm{rec}}$ are the water and methane from the recirculation), i.e., the minimum amount of external water required to avoid carbon deposition is determined by systematically increasing the SCR from 0 to 6.

For each process simulation, heat and mass integration is performed to estimate the best heat cascade utilization and identify the sizes of utilities needed. In this paper, the only hot utility considered is electrical heating. All the operating conditions are checked for carbon depositions by calculating the $\mathrm{C}-\mathrm{H}$ $\mathrm{O}$ molar fractions and positioning them in the ternary plot to verify. The plant efficiency is calculated with other variables, e.g., voltage, overall utilization factor (OUF). Then, the sensitivity analysis is also performed for different single-pass utilization factor (SUF) $(65,75$, $85 \%$ ) and for two extreme biogas compositions (vol.\%): biogas $4\left(\mathrm{CH}_{4} 50, \mathrm{CO}_{2} 45\right)$ and biogas $5\left(\mathrm{CH}_{4} 70 \%, \mathrm{CO}_{2}\right.$ $25 \%)$.

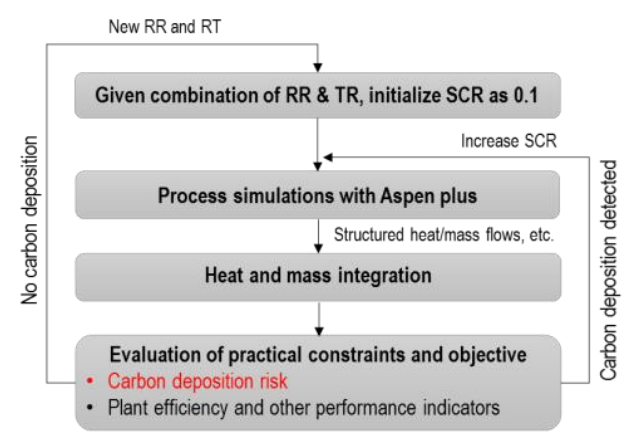

Fig. 2. Flow chart representing the overall calculation procedure.

\subsection{Plant efficiency definition}

The considered performance parameter is the plant electrical efficiency:

$$
\eta_{e l}=\frac{\dot{W}_{e l}^{n e t}}{\dot{m}_{C H 4} \cdot L H V_{C H 4}}
$$

where $\dot{W}_{e l}^{n e t}$ is the net electric power, $\dot{m}_{C H 4}$ is the methane mass flow rate of the biogas, $L H V_{C H 4}$ is the methane lower heating value.

The power consumption of the digestor and the power consumption of the pump and air fan are considered. The power consumption of the recirculation fan is not considered since the fan is driven by a steam turbine with the steam recovered from the waste heat [13].

\section{Results and discussion}

\subsection{Performance map with the minimum water supplied to avoid carbon deposition}

\subsubsection{The HR scheme with SUF 75\%}

The carbon deposition can be eliminated with a feasible operating window extended to a low RT and RR (Fig.
3 ), and a certain amount of external water supplied (Fig. 4).

For a given RT, the efficiency first increases, and then decreases with the increase of the RR, which is caused by the two conflicting effects: (The positive effect is the reduction of the required raw biogas (the increase in the OUF) for fixed SUF and current density. The OUF is increased from $75 \%$ to over $90 \%$ with the RR reaching $80 \%$. The adverse effect is a decrease in Nernst voltage due to the dilution of the fuel by the recirculation flow.

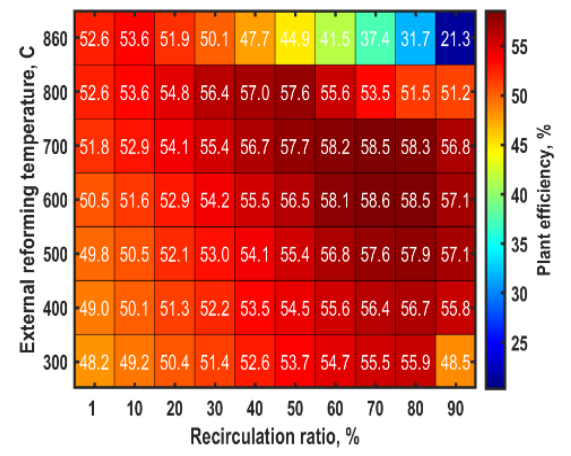

Fig. 3. The operating map of the HR scheme with SUF $75 \%$.

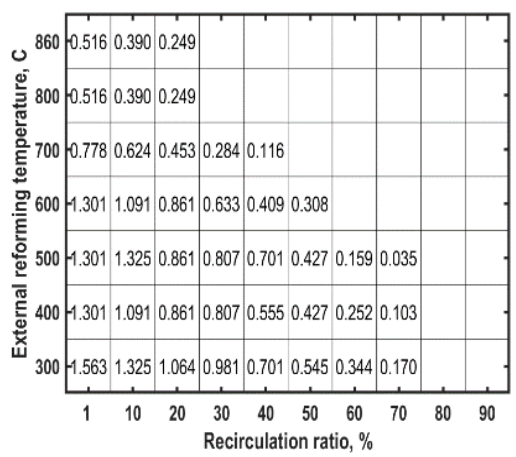

Fig. 4. The minimum amount of external water $\left(\mathrm{sccm} / \mathrm{cm}^{2}\right)$ to avoid carbon deposition for the HR scheme with SUF 75\%.

The efficiency reached at the RT of $800-860{ }^{\circ} \mathrm{C}$ is lower than those achieved at other RTs. The process heat itself cannot satisfy the heat demand of the reforming at such high temperature and the electrical heating will be needed. For a given RR, the increase in RT below $800{ }^{\circ} \mathrm{C}$ always enhances plant efficiency. The external water needed and the dilution of fuel are reduced due to the lower SCR threshold avoiding carbon deposition at a higher RT. The reformed gas mixture has a higher hydrogen fraction due to a higher external reforming ratio, reaching over $70 \%$ with the RT above $600{ }^{\circ} \mathrm{C}$. The electrochemical performance improves with an increase in cell voltage.

Thus, the operating window with peak efficiency (57-59\%) occurs when the RR and RT fall within the ranges of $40-80 \%$ and $500-700{ }^{\circ} \mathrm{C}$. Particularly, this best-performing operating window can be independent of the external water supply. 


\subsubsection{The CR scheme with SUF 75\%}

The CR scheme recirculates mostly $\mathrm{CO}_{2} / \mathrm{CO} / \mathrm{H}_{2}$. The trends of plant efficiency versus RR and RT (Fig. 5) are similar to those of the HR scheme, except that: (1) At a low RT $\left(300-400{ }^{\circ} \mathrm{C}\right)$ and high RR (80-90\%), even with a large external water feed (Fig. 6), the risk of carbon deposition can hardly be removed. (2) The feasible operating points with no need for external water is less than those of the HR scheme since the dry reforming requires high temperature (above $700{ }^{\circ} \mathrm{C}$, Fig. 6) to avoid carbon deposition. (3) With the same RR and RT, the $\mathrm{CR}$ scheme requires more external water to compensate for that knocked out before recirculation.

The operating window with peak efficiency (59-61\%) occurs when the RR and RT fall within the ranges of 60$80 \%$ and $500-700{ }^{\circ} \mathrm{C}$. However, this best-performing operating window still needs the external water supply. The peak plant efficiencies of the CR scheme are higher than those of the HR scheme (57-59\%) since the cold recirculation only introduces the oxygen in the $\mathrm{CO}_{2}$ rather than those in both $\mathrm{H}_{2} \mathrm{O}$ and $\mathrm{CO}_{2}$. Thus, the dilution of fuel (the actual $\mathrm{SCR}$ ) is reduced compared to the HR scheme.

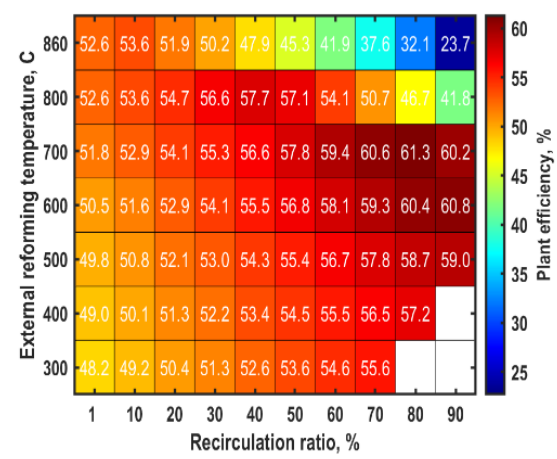

Fig. 5. The operating map of the CR scheme with SUF 75\%.

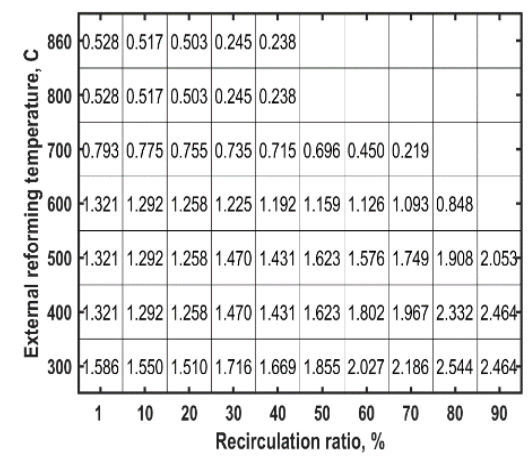

Fig. 6. The minimum amount of external water $\left(\mathrm{sccm} / \mathrm{cm}^{2}\right)$ to avoid carbon deposition for the CR scheme with SUF 75\%.

\subsubsection{The NR scheme}

Since no external reformer is considered for the NR scheme, the efficiency map (Fig. 8) is created by varying the SUF instead of the RT. The peak electrical efficiency reaches over $56.4 \%$ with a high SUF of $75 \%$ and a RR of $70 \%$. Due to the conflicting effects on efficiency described before, a similar trend of plant efficiency versus RR is obtained for a given SUF.

When the RR is over $30 \%$, no additional water for reforming is needed to avoid carbon deposition (Fig. 8). The carbon deposition depends on the internal reforming of the stack at a high temperature of over $750{ }^{\circ} \mathrm{C}$. However, it is worth to mention that, in practice, the NR scheme should work with even higher stack inlet temperature; otherwise, the heat absorbed at the beginning of the anode channel will lead to a big decrease in the temperature, potentially causing too large thermal stress inside the stack. However, with the 0D model, this constraint cannot be verified.

The efficiency of the NR scheme ranges from $50.1 \%$ to $56.4 \%$ for $75 \%$ SUF, which is lower than the HR scheme (57-59\%) and CR scheme (59-61\%), mainly due to the slower electrochemistry. Without an external reformer, the flow of methane at stack inlet increases, and the hydrogen concentration entering the stack decreases, resulting in the drop of the Nernst voltage.

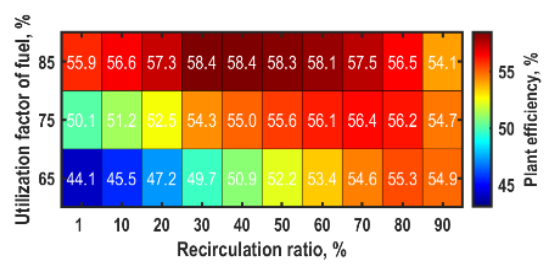

Fig. 7. The operating map of the NR scheme by varying SUF.

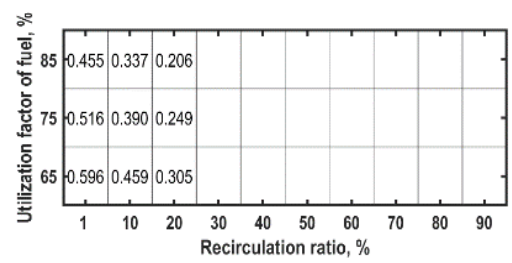

Fig. 8. The minimum amount of external water $\left(\mathrm{sccm} / \mathrm{cm}^{2}\right)$ to avoid carbon deposition for the NR scheme.

\subsubsection{The PO scheme with SUF $75 \%$}

For a given SUF, the plant efficiency (Fig. 9) always increases by increasing RR and $\mathrm{RT}\left(<800^{\circ} \mathrm{C}\right)$. The peak electrical efficiency reaches over $54 \%$ with RT $700{ }^{\circ} \mathrm{C}$ and RR 60\%; however, the efficiency is reduced significantly with a reduced RR and RT and becomes only $10 \%$ at a low RT of $300{ }^{\circ} \mathrm{C}$. This is because the direct oxidation of methane converts a part of the methane into heat rather than electricity. The higher the share of methane partially oxidized, the lower the plant efficiency will be. Therefore, the overall efficiency of the PO scheme is lower than those of the other three schemes. A high RR or RT will reduce the amount of methane directly oxidized, reflected by the air needed for oxidation given in Fig. 10, thus increasing plant efficiency. 


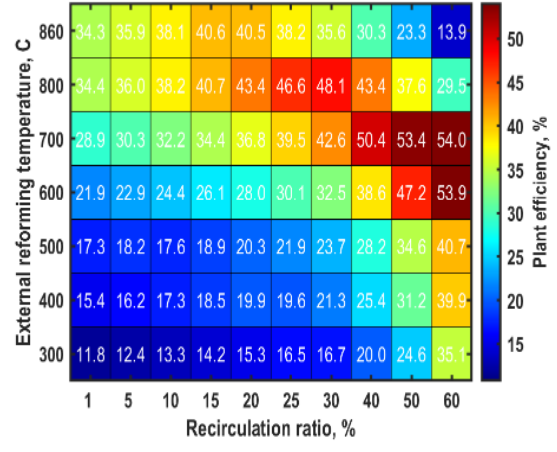

Fig. 9. The operating map of the PO scheme with SUF $75 \%$.

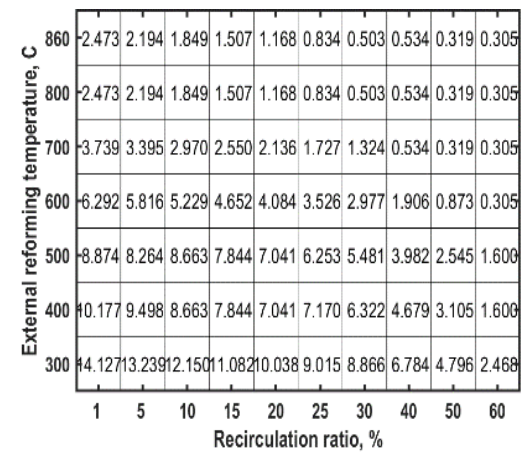

Fig. 10. The minimum amount of air $\left(\mathrm{sccm} / \mathrm{cm}^{2}\right)$ needed for partial oxidation to avoid carbon deposition with SUF $75 \%$.

\subsection{Plant-wise heat integration}

The hot and cold utility heat requirements can be obtained from heat balance of the streams in the grand composite curves (GCC). For each scheme, the curve varies with the RR due to the different heat demand, and we select the representative point to analysis the relationship between the system efficiency and RR.

The shapes of the GCC of the HR, CR schemes are similar, as shown in Fig.11.and Fig.12. The heat release mainly comes from the off-gas combustion, the flue gas cooling. Two main endothermic units are the external reformer and the steam generation if needed. With the increase in RR, the variation of the curves further confirmed the discussion before: (1) a decrease in the off-gas combustion, (2) a reduced use of steam, which eventually reaches zero. The heat demand of the reforming and steam generation is not the bottleneck of heat integration since the overall process is still strongly exothermic even at a high RR. Therefore, it confirms that the trend of system efficiency versus RR is due to the trade-off between the reduction of fuel and the increase in cell voltage. The increase in RR helps improve heat integration with less heat loss to the environment.

With the external reformer removed in the NR scheme and the high RT due to internal reforming, there is no big heat absorption plateau anymore. Also, because of the high RT, the steam required is generally less than those of the HR and CR schemes. The overall process is strongly exothermic with heat recovery potential.
The heat integration of the PO scheme (Fig. 13) is different from the HR and NR schemes: (1) The additional heat released by the direct oxidation of methane, particularly at a low RR (e.g., 20\%), results in higher heat losses and thus a significantly low plant efficiency. Also, at the RR of $20 \%$, the heat released from the direct oxidation of methane is even more than that required by the reforming of the remaining methane; thus, there is even a net heat release from the reformer. With the increase in RR, the reformer releases less heat, reaches auto thermal (at around 35\%) and becomes endothermic afterward, since the share of methane directly oxidized is reduced. (2) There is no steam generation at all, which is in line with the purpose of the PO scheme.

Therefore, from the heat integration viewpoint, the overall processes of all schemes are strongly exothermic and can fully support the complete external reforming. Heat integration does not hinder the enhancement of plant efficiency.

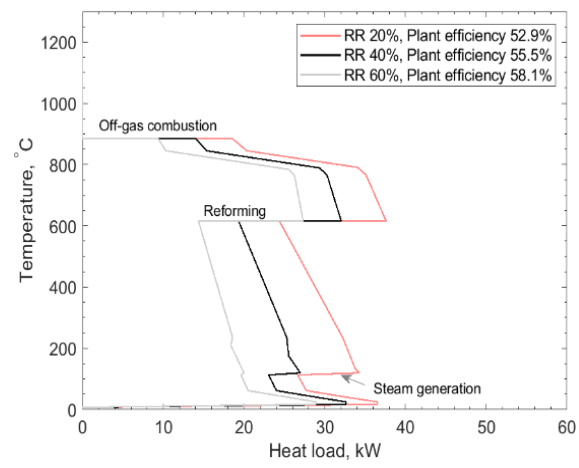

Fig. 11. Grand composite curve of the HR scheme with SUF $75 \%$ and RT $600^{\circ} \mathrm{C}$.

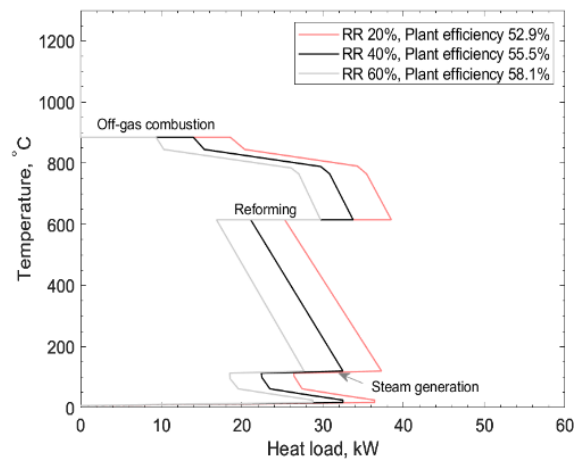

Fig. 12. Grand composite curve of the CR scheme with SUF $75 \%$ and RT $600{ }^{\circ} \mathrm{C}$.

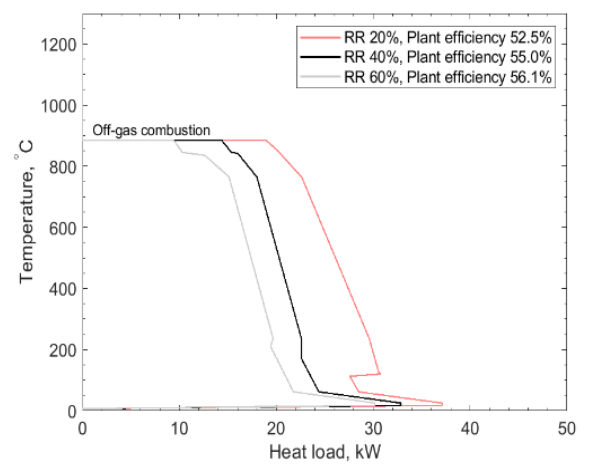


Fig. 13. Grand composite curve of the NR scheme with SUF $75 \%$.

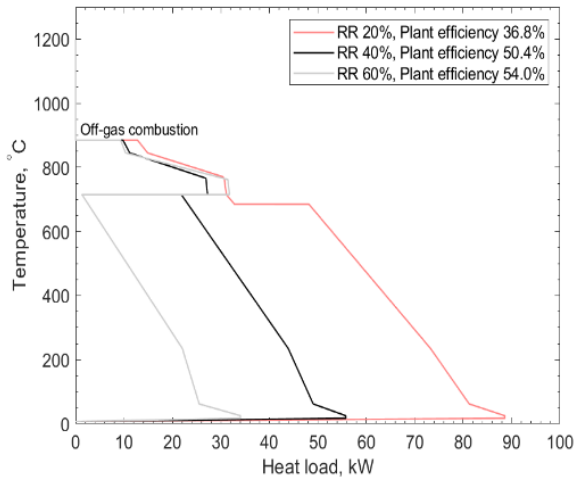

Fig. 14. Grand composite curve of the PO scheme with SUF $75 \%$ and $\mathrm{RT} 700{ }^{\circ} \mathrm{C}$.

\subsection{Efficiency Comparison}

The maximum plant efficiency of the four schemes for all three SUF is compared in Fig. 15. The CR scheme achieves the highest efficiency of $60-63 \%$, followed by the HR scheme (2-3\% points less), due to the effect of fuel dilution on the electrochemical performance. However, the CR has a narrow operating window to be independent of the external water. The efficiency of the NR scheme is low (56-58\%), mainly due to worsened electrochemistry by the local hydrogen concentration. The PO scheme provides a similar level of plant efficiency (55-58\%) as the NR scheme. However, a part of the methane is directly oxidized rather than being reformed; therefore, for the same current density and SUF, more methane is needed which leads to lower efficiency. NR and PO reduce the system complexity

The variation of the biogas composition has a limited impact on the plant efficiency with a change of less than $2-3 \%$ points 4 and 5 . It is also shown that the higher the $\mathrm{CO}_{2}$ fraction, the lower the efficiency will be.

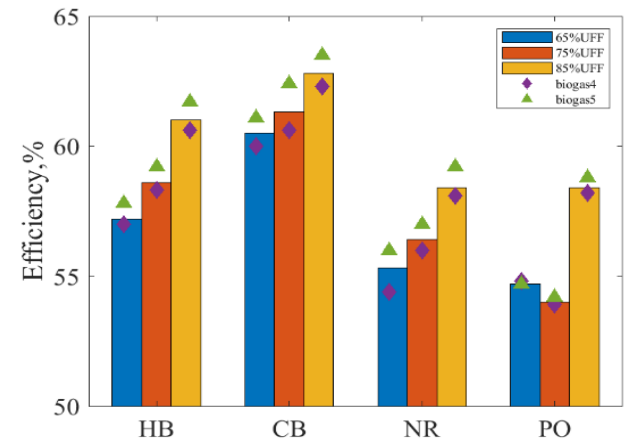

Fig. 15. Optimal efficiency of four schemes for different biogas and SUF.

\section{Conclusion}

Four schemes of the biogas fed SOFC plants with different types of anode off-gas recirculation and reformer were compared in this paper with a sensitivity analysis of plant efficiency on the reforming temperature and recirculation ratio. The sensitivity analysis was performed to different single-pass utilization factor and biogas compositions. For each combination of reforming temperature and recirculation ratio, the minimum external water needed to avoid the risk of carbon deposition is determined.

The results shown that the HR, CR schemes can be independent of external water without the risk of carbon deposition at RR 40-80\% and RT 500-700 ${ }^{\circ} \mathrm{C}$. However, the operating window of the $\mathrm{CR}$ scheme is narrower. The CR scheme achieves the highest efficiency (60$63 \%$ ), followed by the HR scheme (58-61\%), since the electrochemical performance of the CR scheme is less affected by the dilution of the fuel.

The NR and PO schemes can also avoid carbon deposition without external water. However, the plant efficiency is lower (55-58\%), which is due to the dilution of fuel for the NR scheme and the more methane consumption for the PO scheme.

The variation of biogas composition has a limited impact (2-3\% points) on the plant efficiencies for all schemes. The higher the $\mathrm{CO}_{2}$ fraction in the biogas fed, the less the plant efficiency will be.

\section{Acknowledgment}

This work has received funding from the European Union's Horizon 2020 under grant agreement No 826234 (Waste2Watts), 826161 (Waste2GridS), 815284 (BLAZE) and 735692 (CH2P), and, and support from the Fuel Cells and Hydrogen Joint Undertaking, Hydrogen Europe and Hydrogen Europe Research.

\section{References}

1. M. Goor, S.Menkin, E. Peled. Int J Hydrogen Energ 44, 5 (2019).

2. J.Rechberger, A.Kaupert, J. Hagerskans. Transp. Res. Procedia 14, 3676-3685 (2016).

3. Y. Bessekon, P. Zielke, A. C.Wulff. Int J Hydrogen Energ 44, 3 (2019).

4. F. Curletti, M. Gandiglio, A. Lanzini, M.Santarelli, F. Maréchal. J Power Sources 294, 669-690 (2015).

5. V. Liso, A. C. Olesen, M. P. Nielsen, S. K.Kær. Energy 36, 4216-4226 (2011).

6. L. Barelli, A. Ottaviano. Energy 71, 118-129 (2014).

7. B. Tjaden, M. Gandiglio, A. Lanzini. Energ fuels 28, 4216-4232 (2014).

8. A. Plus, Aspen Plus user guide. Aspen Technology Limited, Cambridge, Massachusetts, United States (2003).

9. L. Wang, M. Pérez-Fortes, H. Madi. Appl Energ 211, 1060-1079 (2018).

10. G. Loreti, A. L. Facci, I. Baffo and S. Ubertini. Appl Energ 235, 747-760 (2019).

11. G. Loreti, A. L. Facci, T. Peters and S. Ubertini, Int J Hydrogen Energ 44, 4508-4523 (2019).

12. L. Wang, M. Rao, S. Diethelm, T.-E. Lin. Appl Energ 250, 1432-1445 (2019).

13. P H. Wagner, Z. Wuillemin, D. Constantin. Appl energ 262, 114219 (2020). 